\title{
University of
}

Sugarman, Leonie (1995) Action man: an interview with Gerard Egan. British Journal of Guidance and Counselling, 23 (2). pp. 275-286.

Downloaded from: http://insight.cumbria.ac.uk/id/eprint/700/

Usage of any items from the University of Cumbria's institutional repository 'Insight' must conform to the following fair usage guidelines.

Any item and its associated metadata held in the University of Cumbria's institutional repository Insight (unless stated otherwise on the metadata record) may be copied, displayed or performed, and stored in line with the JISC fair dealing guidelines (available here) for educational and not-for-profit activities

provided that

- the authors, title and full bibliographic details of the item are cited clearly when any part of the work is referred to verbally or in the written form

- a hyperlink/URL to the original Insight record of that item is included in any citations of the work

- the content is not changed in any way

- all files required for usage of the item are kept together with the main item file.

\section{You may not}

- sell any part of an item

- refer to any part of an item without citation

- amend any item or contextualise it in a way that will impugn the creator's reputation

- remove or alter the copyright statement on an item.

The full policy can be found here.

Alternatively contact the University of Cumbria Repository Editor by emailing insight@cumbria.ac.uk. 


\section{ACTION MAN: AN INTERVIEW WITH GERARD EGAN}

Leonie Sugarman, Department of Health Studies and Human Sciences, University College of St Martin, Lancaster LA1 3FD, UK

British Journal of Guidance \& Counselling, June 1995

Gerard (Gerry) Egan is Professor of Organization Studies and Psychology and Director of the Center for Organization Development (CORD) at Loyola University of Chicago. His doctorate is in clinical psychology. He writes and conducts workshops and seminars in counselling, counsellor education and training, organisational effectiveness, management development, leadership, the management of innovation and change, and organisational politics and culture. He consults to a variety of companies and institutions, both in the United States and abroad. He has worked in England and other pans of Europe, Canada, Australia, Africa, China and Japan. His book The Skilled Helper (Egan, 1975) is now in its fifth edition (Egan, 1994a). Reference was made to these, and the intervening editions (Egan, 1982, 1986, 1990), during the course of the present interview. Adding Value: a Systematic Guide to Business-Driven Management and Leadership (Egan, 1993) reflects Professor Egan's involvement with organisations. His latest book (Egan, 1994b) concentrates on managing the nonrational or what he terms the shadow side of organisations. It mirrors his long-term interest in the shadow side of helping (Egan, 1986). Other issues addressed in his publications have included group work (Egan, 1973, 1976), community-level interventions (Egan \& Cowan, 1979) and change-agent skills (Egan, 1988a, 1988b). He was interviewed for the British Journal of Guidance and Counselling in London in July 1994. The interview was tape-recorded, and Professor Egan was sent the edited transcript for comment. He asked for no changes to be made, preferring, in his words, 'to leave it as it tumbled out'. He invites comments and queries to be addressed to him at Loyola University, $820 \mathrm{~N}$. Michigan Avenue, Chicago, Illinois 60611, USA.

Leonie Sugarman: The aspect of your work for which you are best known, certainly to audiences such as readers of the British Journal of Guidance and Counselling, is the model of helping you have described and developed over nearly twenty years in five editions of The Skilled Helper.

Gerry Egan: I did not invent the model--it's called problem management, or problem solving, or opportunity development. I'll be so bold as to say that no matter what form of therapy or counselling one uses, the basic dynamics of this process are played out in it. I don't see it as an ego trip: it is not 'The Egan Model'. I simply have my version of it. I would now go so far as to say that the model has to do with the structure of the human mind and the way we think about change.

LS: So what you're describing is a natural process?

GE: It's a natural process that plays itself out in any successful counselling, therapy, or other type of helping. And in my experience it's validated by the way it travels across cultural lines. The Skilled 
Helper has now been translated into a range of European languages, and also into Chinese and Japanese. I've dealt with it in training sessions with Chinese and Japanese--mainly through interpreters, obviously. They understand it. It makes sense. They can use it. It's not part of a particular culture. There are cultural modifications to the process, as there should be. There are individual modifications to the process too. If clients are relatively free and in charge of their lives, then the model becomes a counselling model, based on free choice.

But let's look at the opposite end of the continuum. Let's say that I have a patient who's psychotic, who is not in charge of his or her own life and with whom dialogue is almost impossible. At this extreme the same process becomes a case-management model: what are the issues around this client, or patient? What is best for this client? What methods of intervention can we use? And how do we implement them most efficiently and effectively in the service and needs of this client?

So there is a continuum from where the client is fully in charge of his or her life to where the client isn't in charge of his or her life at all. All I'm doing is anchoring the continuum. At one end it is a counselling model, and at the other end it is a case-management model. We also have every gradation in between. So something like guidance--which is in the title of this journal but in my experience is not now a term used that often in the USA--is down the continuum a bit, where the model becomes an educational model and the helper, the counsellor, the guidance professional is actually providing suggestions to people. In the same way, parents provide guidance for their children in all dimensions of life as the child, the adolescent, the young person travels on the route towards adulthood and the capabilities of making free choices, fully informed choices. So the process can be used in a whole variety of ways. And with any given client I might find myself moving into guidance mode rather than free-form counselling.

LS: One of the things that I did in preparation for this interview was to look back through the different editions of The Skilled Helper. In the first edition you write about the influences on the model, mentioning Carkhuff, Rogers, social influence theory and the principles underlying behaviour change.

GE: Yes. And those things are still part and parcel of the whole process.

LS: Then in the second edition you introduced the idea of helping as problem management and the helper as a consultant to the client. In 1982 this was quite a novel definition of counselling and counsellors.

GE: Yes, that's right. But note how it's very much towards the freedom end of the pure-form counselling to case-management continuum. Development of that continuum came later. 
LS: In the third edition you express--and here I quote from the Preface--'my growing concern about what I view as an over emphasis on the first stage of counselling, problem definition and insight'.

GE: Yes. I haven't got the scientific or demographic studies on this. My fears arise from the way I very often see a text such as The Skilled Helper being used, with some instructors never getting beyond the communication skills. I think that later on helpers tend to do what they've been trained to do, and if they're trained to do Stage I, then they do Stage I. However, I think that for clients most benefits of the counselling process, or many benefits of the counselling process, lie down the line in helping them determine what they want. I'm very concerned that we truncate the process, that we over-emphasise Stage I. I haven't done the studies, except informally in my own mind, but I suspect that if you were to review all current forms of helping you would find that a lot of them emphasise the skills of what I call Stage I. They focus a great deal on insight. To tell you the truth I find many of them extremely useful. They come up with a whole range of inventive methodologies, and they enable the counsellor, the helper, to help the client explore things much more fully and creatively. But that's where it ends. The assumption is always a kind of Rogerian assumption: 'If the person understands, the person acts'. And I don't think that's true. I don't find that true across the world. It's true for some, but not for all. I can understand continuing to develop what I call the communication skills, the insight-focused methodologies and things like that, but I want to take it further. Another way of looking at Stage I in the way I describe the helping model is as the development of a set of storytelling competencies that can be used throughout the whole problem-management process. The story can be told about the preferred scenario area, or the goal-setting area, just as well as the problem area. And when it comes to ways of getting at action strategies--there's a story embedded in that too.

LS: The third edition of The Skilled Helper appeared in 1986. Back in 1979, in your book written with Michael Cowan, you present a four-stage version of the model, with the fourth stage comprising implementation and evaluation. You have never incorporated this stage into The Skilled Helper series of books. Indeed, in the preface to the third edition you express thanks to one of your graduate students for saving you from the temptation to do so 'by suggesting that I place evaluation at the center of each stage'.

GE: Yes. Part of that came from my move more towards business, industry and the workplace.

Because, although we might like to mystify it, counselling is another form of work, and in work there needs to be quality assurance. If this is in the hands of the director of quality at the end, it's too late. It must be built into the process and everybody must be a quality-assurance person. There is an evaluative dimension to quality assurance at work; analogously, I think the same is true of the counselling process. A type of upbeat 'criticism', in the best sense of that term, must be part and parcel of it all the way through. Evaluation is, to me, extremely important. It's part of the leverage component. We shouldn't be wasting our time--the counsellor's time or the client's time.

LS: That explains why evaluation should be part of the whole process rather than coming along at the end, but what about implementation, the first step in your putative fourth stage? In the third edition of The Skilled Helper you placed implementation of action plans as the final step in stage three; then in 
the fourth edition, stage three ends with the development of action plans, with action implications being denoted by an 'action line' underpinning all three stages.

GE: Let me say a few things about that graphic. The graphic shows three circles which look like snails digging into a line underneath. Each circle digs into that line. The three circles or the three snails, whatever you want to call them, are concerned with talking about change, with planning a change. I also accept that re-education is taking place and therefore change might well be taking place through the actual relationship that is being built up between client and counsellor. But, that aside, the dialogue is largely about planning to change; it isn't change itself. We can give a name to Stage I--let's call it 'Blah'. Stage II--let's call it 'Blah'. Stage III--let's call it 'Blah'. Unless action that gently moves the client west, or wherever constructive change is, takes place within and throughout the whole process, then it's nothing but 'Blah! Blah! Blah!'.

LS: So you see action, like evaluation, as an integral part of Stage I, Stage II and Stage III. GE: Yes. It's part and parcel of the process. It's the fruit of Stages I, II and III. LS: My concern, particularly when the model is covered rather briefly and superficially, is that this action line may in fact be ignored. I do hear the model being referred to as a 'three stage model', without reference to the action implications.

GE: It should be 'a four-dimension model' or something like that. If the action line comes across as possibly an afterthought, maybe I should take the arrow and put it right in the middle--through the heart, as it were. Because it is the heart of the matter. If clients don't act on their own behalf, change does not take place. Maybe the best predictor of the success of counselling is what the client does between the first meeting and the second meeting. If the client doesn't do anything, this might be the best indicator that the process is getting us no place and we need to do something radical about it. Now the action might be inside. It might be changing attitudes. It might be very cognitive in nature, but even the cognitive changes that take place get translated into the external life of the client in one way or another--in relationships, in relationships to self, in demeanour changes. In the text I always ask: 'What are the action implications of this stage? What are the action applications of this stage?' And I actually force people to deal with it in some sense in the exercise book by saying: 'When you have a dialogue at this part of the model, what are some of the things the client could actually do in his or her day-to-day life at this stage, even without some grand plan for constructive change?'

LS: In the fourth edition, as well as introducing the action line and reversing Steps B and C in Stage I, you say in the Preface that 'this edition relies a little more on the clinical instinct of its author, and a bit less on micro research'.

GE: We have an awful lot of micro research that is done for the sake of doing it. I agree totally with Carl Rogers when he said in his own unassuming way: 'I don't find much of the research in counselling and psychotherapy to be that helpful'. I do find, however, the thematic dimensions of research quite useful--seeing the same themes emerging again and again in different settings. Things 
like clients' problem-solving abilities, which is now a constant topic of research in the United States. There are two elements to this-the actual problem-solving abilities of clients and also the client's perception of his or her abilities. They might not be the same thing. There is a personality dimension to it, in that diminished perception of the ability to solve problems is related to the whole area of selfefficacy. I think this is extremely important for the counselling profession.

So I do see a place for research. It informs my clinical instinct. The metaphor I use is the gestalt one of figure and ground. The models, methods and skills that we're talking about are the ground, and when I talk about clinical instinct it's from that ground. The clinical instinct is the figure in the gestalt sense. But it's not magic. In a sense I work instinctively, but it's not instinctive. I'm doing it out of the amount of learning that has taken place over a lifetime. And it's organised learning. It isn't chaotic learning, or haphazard learning, where I move from path to path.

LS: When we come to the Preface to the latest, fifth edition of The Skilled Helper, one of the things that interested me was your description of the model as more client-focused than process-focused.

GE: Yes. I think that as I've moved through these various editions I've moved more and more towards a common language-that is, the language of the client rather than the language of the professional. For instance, in the fifth edition I advocate asking clients, in Stage II: 'What is it that you want?'. So, if the clients are a married couple who are having all sorts of problems for various reasons, then the basic question for Stage II is: 'All right, what type of marriage do you want? What do you want this relationship to look like?' And that is the language of the client rather than the counsellor.

LS: Another issue highlighted in the Preface to the fifth edition is what you call the shadow side of helping-'those things better left unsaid', as you quote one British observer as saying.

GE: This has to do with what's really going on behind the helping process. What are really the dynamics between counsellor and client? What are the real intentions of the client? I like to take a pragmatic, common-sense approach to this rather than, say, a psychoanalytic or psychodynamic approach. I think there is a general need to demystify the profession. We tend to mistake mystification for professionalism. They are not the same. We are professional to the degree that our clients live more effectively, or at least are in a situation where they can choose to live more effectively if they want-that is, they're more capable of living effectively. That's what I think is the essence of professionalism. And this relates to one of my strongest interests fight now-the distinction between professional and academic models.

LS: What do you mean by these terms? 
GE: Let me describe them a bit. I see another continuum, in a sense. At one end of the continuum, we have academics in terms of the theoreticians and researchers. At the other end, we have practitioners. That's usually the dichotomy that's given. In the United States we also create what I see as a fiction. This is the 'research practitioner'--that's the term officially adopted by the American Psychological Association. I do not think that person, generally speaking, exists. Statistics in the United States-and I can't be held to the exact number in this-show some $90 \%$ or more of people who get a degree in clinical psychology do no more formal research afterwards. So, using the 'researcher practitioner' paradigm actually out there in the workplace, the counselling workplace, is a fiction. They don't do it. And I think one of the reasons they don't is because of what happened to them in academic settings. That is, research has been made aversive in academic settings.

So, what I think we should have between the two ends of the continuum, the theoretician/researcher and the practitioner, is a much narrower group which, in partnership with practitioners, focuses on what I call 'research that makes a difference'. This is a role which I think I have played over the years, to tell you the truth, and some others have played too, and which should be developed within the profession. I call that role, for want of a better term, the 'translator'. The translator, whilst not doing research, understands the dynamics of research, and can identify good research--especially research that's translatable into the models, methods and skills that practitioners need to become more effective and efficient in what they do.

LS: These distinctions between the theoretician/researcher, translator and practitioner relate to work roles. What about the training implications?

GE: I'm convinced that we have to deal with the distinction between professional programmes and academic programmes. So I've revisited the whole notion of 'Can you have a bona fide professional programme in an academic setting?'. I think the jury is out on that. Currently, I lean towards saying 'I doubt it'. The reason I say this comes from my experience that whenever you have a professional programme in an academic setting, the academic culture overwhelms the professional culture. All the rules, regulations, norms, beliefs, values and so forth of the academic setting end up taking precedence. I can understand giving the doctoral degree to the theoretician/researcher. I can understand giving the doctoral degree to the translator. But I'm not so sure any more that the doctoral degree should be the degree of preference for the practitioner in the way it has been in the United States. A fair amount of research has shown that when it comes to productivity or effectiveness, paraprofessionals can do as well as professionals, meaning that the doctoral degree--if that's all they do--doesn't add a great deal of value. For the counsellor it should be a question of life-long learning from a professional base. There's a lot of mythology around academic qualifications. We talk about depth and breadth and all that sort of stuff, and I'm not so sure they get it.

Here's how I currently think. I would like to see a professional programme in counselling that would train translators and practitioners, and what I'll try to do here is describe what I see as the dimensions of the professional programmes. I start off by saying professional programmes can be as rigorous and sometimes more rigorous than academic programmes. They should be professionally rigorous. We 
have the fiction that if they are academically rigorous they are also professionally rigorous, and that's ludicrous. Sometimes it's just the opposite.

LS: What do you mean by professionally rigorous?

GE: By professional I mean somebody that can actually deal with clients and engage in the overall goal of the helping process so that, because of the transactions which take place between client and counsellor, client and helper, the client is capable of managing the problems of his or her life more effectively--whether they're internal, external, relational, or whatever. Now--the curriculum. I think most counselling takes place through dialogue; therefore the communications skills part of the curriculum needs to be rigorous. We can't afford practitioners that are not expert and adept in the range of communication skills that I and many others now talk about in the helping professions. That's not an academic exercise. That's a professional exercise. So I would like to see competency-based professional programmes, where you cannot leave a programme that gives some kind of qualification-diploma, degree or whatever--without demonstrating, hands down, a high degree of adeptness in the essential tools for counselling and psychotherapy. Full stop. If you can't do that you don't get the degree, you don't get the qualification, and you cannot make up for it by adding academic programmes.

Basically my approach to teaching communication skills is to get people started so that they fully understand what is involved. When it comes to something like empathy, I show them tapes of Rogers because he was a master at empathy. It's not the only communication skill, but when trainees say 'What standards are we to be held to?', I'll play the tape with Rogers and I'll say: 'There it is. When it comes to empathy, that's what we're aiming for.' They can't do that, but they can get started and get some initial skill within--I won't say classroom settings, I'll say workshop settings. But unless these skills become part and parcel of the day-in and day-out life of the helper or helper-to-be, it doesn't make any difference. They can't get adeptness within the workshop setting. The process can begin there, but they must get adeptness out there in real life, because the communication skills need to become second nature to people. They're such essential tools to the helping process, no matter what helping model you use.

So that would be challenge number one. Challenge number two would be the helping process, and the process I use is that in The Skilled Helper. A friend of mine at the University of Melbourne said this to me once: 'If I have two years, I do the entire model. If I have one year, I do the entire model. If I have six months, two hours, two minutes--I do the entire model'. We must take the human process represented in the model and present it as a whole. We short-change the profession and we shortchange our clients if we truncate it.

LS: You mentioned the workshop setting in terms of training in communication skills. Do you see that continuing for all elements of the helping process? 
GE: Yes. Absolutely. Because when I talk about the training process, I talk about various steps. Step number one is reading or a lecture, so students understand something of the process--whether it's challenging, goal setting, issues around implementation of programmes, or whatever. They need to understand the entire process and each part of the process. Secondly, I talk about written exercises in modelling to provide a behavioural feeling for the process. Then I talk about actual practice and feedback and so on, which gives them the 'doing' feel--the actual professional feel. And then the fourth stage is, number one, doing it, doing real counselling under supervision; and number two, lifelong learning--that is, taking counsel with myself and with my colleagues around the entire process so that in a life-long way I get better and better at this process. If I do that, it means I also become more capable of training both clients and colleagues in the process. So that's how I would see the training process: the professional approach to it looks quite different from the academic approach, even in academic areas.

LS: Can we move on to the issue of the academic element in professional programmes?

GE: Yes. Let's take something like developmental psychology. Everywhere I go, I ask people: 'Do you have developmental psychology in your programme?' And they say: 'Of course'. When I ask them what it's like, they say: 'Well, we read these books'. And the books are mainly books on theory and research across the life-span or on one part of it. The books are not geared to professionals. They're geared to people who are either going to teach in an academic way or do research with respect to developmental issues across the life-span. And very often they say: 'Well, we got stuck in childhood'. The book was on the life-span, but it's like training people in the skilled helper model, they don't get beyond stage one.

But there's a completely different way in which developmental psychology can be approached, through what I call the Eriksonian or the Levinsonian approach. Both of them deal with life stages. They're not neat--if you want strictly researched topics; but professionally they're very useful. Within the life stages you can talk about the developmental demands, developmental challenges, developmental tasks and normal developmental crises that, generally speaking, occur within any given culture. Eras and stages might be spelled out somewhat differently in a Japanese society from, say, a Samoan society, but all societies generally have these developmental stages.

When it comes to professional training in developmental psychology, my starting point would be: 'What's the developmental stage of the learner?'. Students would learn everything they could about their own developmental stage, developmental demands, developmental tasks, and normal developmental crises, asking: 'Where do I stand with respect to these?'. That is task number one. Task number two might be interviewing someone at the same developmental stage. This is not counselling so much as getting a better feel, getting more rooted in what the developmental issues look like in the lives of different people. Then I would have people interview one or two or three people from every major developmental stage, or at least the major developmental stages in which they will probably do 
their counselling--anything from adolescence right through to old age. This would be to get, not an academic, but a professional understanding of what the issues and challenges are like.

And this is just the beginning. The type of learning that starts like this can become a life-long process. And it can be a very rigorous and demanding process. But it's rigorous and demanding in a professional rather than an academic sense.

So you get the idea of how I would teach developmental psychology in a professional setting. The academics might scream and yell, but I don't care. What I would like is for them to continually do the research, and the translators to continually look at that research and continually upgrade the professional training based on the best of the research that is found in developmental psychology.

So that would be one example. We could do the exact same thing with personality psychology. The way it's taught now is as a theory/research discipline--we see all of these findings and say: 'Isn't that interesting?'. What if, instead of that, we started with 20 key ideas that are relevant to the counselling profession, that have developed over the last 20 years through theory and research in personality development, and looked at them? Let me pick one out of the hat--internal/external locus of control. Type A/Type B personality would be another one that seems quite relevant, especially in a chaotic society. So it would go something like this: 'Does that relate to the way people live out their lives?'--of course; 'Does that relate to the problems and opportunities of one's life?'--of course it does. So first I would seek a full understanding of all of that in terms of myself: 'Where do I stand?'. I would do some testing of the idea with respect to myself, and then interview some other people so that eventually I understand very thoroughly each of these major contributions to personality theory. The aim would be to ground in the professional an understanding of how you take personality theory and research and translate it into your own life and the lives of the clients that are in front of you.

LS: So you are continually asking: 'What does this concept mean for me as a person, and for my client?'.

GE: That's right. And I see this as very interesting, challenging, exciting and rigorous. I'm going to give you one other example, and that's statistics. You might say: 'Why statistics? How does that relate to the whole thing?' I would answer that it depends on how statistics is taught. It needs to be taught as a way of knowing, as an epistemology, rather than as a set of mathematical formulas. I think the statistical mentality, the research mentality, is extremely important because in a certain sense my work with the client is a type of action research.

Let me give you a couple of examples from statistics. Let's take sampling theory. When I'm with a client, I'm sampling the client's behaviour. This is not the whole range of the client's behaviour. I can make sampling mistakes. So understanding and using statistics and research methodologies as 
epistemology helps me, as it helps people doing research, to avoid making stupid mistakes with my clients, drawing the wrong inferences.

Similarly with probability theory: I think that is extremely important in the helping process because very often in working with clients we're dealing with discretionary change, change they don't have to engage in. What I need to be concerned with is the probability that what I'm doing relates to the clients actually engaging in constructive change. So the whole mentality of statistics and research methodology is germane to the professional process, but not as it is currently taught, as an academic discipline or a strictly research discipline.

LS: So it's taking the concepts of statistics rather than the techniques.

GE: That's right. Certainly not the mathematical derivations and formulas. I think that's totally irrelevant, even though very often that's the way its taught.

LS: So far we've been concentrating on the counselling field, and I'm aware that over the years your interests have moved more towards organisational consultancy. Can we turn to that area now?

GE: I consult organisations, companies, institutions, enterprises with respect to their business--from strategy fight on. But I also deal with the quality of management, managerial problems and the problems of managers, and I have ended up doing a great deal of counselling in the consulting work that I do. I tend to talk about it in terms of personal issues around business problems, or coaching and counselling, to make it more workplace-focused, with coaching focused on the development of potential, and counselling talking about the obstacles within the person to greater productivity. But it's still basically the same process. Obviously, in the workplace managers are not meant to be psychologists, and they're not meant to deal directly with personal life problems. Workplace problems, productivity problems are centre stage, with things like social-style dimensions, which interfere with productivity, on the margins. Managers tend not to deal with personal problems. If an employee's marriage is falling apart, it may impact on what is going on in the workplace, and then this may become an issue. But the actual help for the marriage problem doesn't take place in that forum.

LS: Your recent book in the consultancy rather than the counselling area is Adding Value, in which you present three models of management, one of which is a version of the skilled helper model for organisations.

GE: Yes, that's Model B, and it's basically a model for constructive change--which is another way of looking at the skilled helper model. It can be used as a coaching/counselling model in the business sense, and also in relation to the kind of massive changes that institutions today are involved in where 
all staff must be agents of change. Managers must know what's going on out in the environment and be ready to react very quickly to the changes that are taking place within their industry. They need to be agents of change in that reactive sense. But that's not enough. They must also be agents of change in a much more proactive sense. They must initiate innovation and change to keep the company somewhere near the edge of what's going on in their industry, or they're not going to flourish. And a shared model of constructive change can be a tool for a more competitive edge. Most companies don't have such a model or shared language for talking about issues and problems. Model B can fill that gap.

LS: However, in Adding Value you describe Model A as primary [1].

GE: Model A is primary in the sense that the psychological concepts we talked about earlier are primary in relation to counselling--things like a life-stage approach to developmental psychology and personality dimensions such as self-efficacy. These are dimensions of life. In the same way, Model A identifies the crucial dimensions in making some kind of system work. Model A provides the principles that enable you to do an assessment of what the key issues are in a place, a company, an institution--just like developmental psychology helps you to collaborate with the client on an assessment of the key issues within the client's life. It also provides principles with respect to when a company is really doing well, or when an institution or a social service agency is really run well. Model A doesn't provide the formulas, but it provides the principles.

LS: And then there's Model C, which you describe as the shadow side of organisations [2].

GE: That's right. The technology of change, say for managers, is now relatively simple. But the shadow side of change is relatively complex and difficult. The change process in a model like the skilled helper model looks very two-dimensional, whereas in real life it's very much threedimensional. So I'm saying: 'What is behind it? What are the realities behind this model, or any pieces of the model?'. This applies to Model A and to Model B. So in a certain sense the shadow side is not a third model but another dimension to the other two main models. And the same is true of the helping process--questions like: 'What's really going on here? What are really the dynamics between counsellor and client? What are the real intentions of clients?'

LS: We've already had a lengthy and wide-ranging discussion, but I was wondering if there was anything you wanted to add to what has been said?

GE: Well, I guess my passion currently is 'How can we give away effective management?'. The fact that things like the skilled helper model do cross borders makes them extremely powerful tools because they can be shared across cultures. And because that process is part of our common human heritage, we can as helpers and clients own it conjointly. I can become not a helper in the sense of the 
more knowing giving to the less knowing, or the more capable to the less capable, but a helper in the sense of collaborator.

Another point that I've mentioned already but would re-emphasise before we depart is the nature of discretionary change. If you're at the case-management end of the continuum, you are not dealing with discretionary change on the part of the client, because you are making decisions for clients who cannot make decisions for themselves. When you're down the other end of the continuum, very often the change you are dealing with is discretionary change--change the client does not absolutely have to engage in. The track record for discretionary change, both in institutions and in the lives of us individuals, is poor. I think we should admit up-front that as counsellors we are very often dealing with areas of discretionary change. That's the very nature of the beast. The whole idea is how can we admit that we are dealing in an area of discretionary change, and help the client to understand its dynamics and to overcome some of the obstacles to discretionary, constructive change in their lives. I try to do that now in the midst of institutions.

I think we're in a profession that has a certain fragility to it. We should admit that. We cannot change the lives of our clients. And clients find it very difficult in discretionary ways to change their own lives. Counselling is still a very noble profession, and an essential profession. But we should understand the dynamics of the profession itself.

LS: And understand its limits.

GE: Exactly. Only if we understand its limits can we push its limits.

Notes

[1] Model A, Business and Organisational Processes, is a pragmatic overview which managers can use to review the needs of their business and of the organisation that serves the business. It can also be used to design, manage or assess an entire corporation, company or institution, any of its sub-units, or any function, project or programme. It has six key elements: Strategy; Operations; Organisational and Job Structure; Human Resource Management Systems; General Management Systems; and Leadership.

[2] Model C, Shadow Side of the Organisation, provides a framework for helping managers and other agents of change deal with aspects of the system that are other than rational. It has five key elements: Business and Organisational Messiness; Employee Idiosyncracies; The Social System; Organisational Politics; and Organisational Culture. 
References

EGAN, G. (1973) Face to Face: the Small Group Experience and Interpersonal Growth (Monterey, CA, Brooks/Cole).

EGAN, G. (1975) The Skilled Helper: a Model for Systematic Helping and Interpersonal Relating (Monterey, CA, Brooks/Cole).

EGAN, G. (1976) Interpersonal Skills: a Skills/Contract Approach to Human Relations Training in Groups (Monterey, CA, Brooks/Cole).

EGAN, G. (1982) The Skilled Helper: Models, Skills, and Methods for Effective Helping, 2nd edn (Monterey, CA, Brooks/Cole).

EGAN, G. (1986) The Skilled Helper: a Systematic Approach to Effective Helping, 3rd edn (Monterey, CA, Brooks/Cole).

EGAN, G. (1988a) Change-Agent Skills A: Assessing and Designing Excellence (San Diego, CA, University Associates).

EGAN, G. (1988b) Change Agent Skills B: Managing Innovation and Change (San Diego, CA, University Associates).

EGAN, G. (1990) The Skilled Helper: a Systematic Approach to Effective Helping, 4th edn (Monterey, CA, Brooks/Cole).

EGAN, G. (1993) Adding Value: a Systematic Guide to Business-Driven Management and Leadership (San Francisco, CA, Jossey-Bass).

EGAN, G. (1994a) The Skilled Helper: a Systematic Approach to Effective Helping, 5th edn (Monterey, CA, Brooks/Cole).

EGAN, G. (1994b) Working the Shadow Side: a Guide to Positive Behind-the-Scenes Management (San Francisco, CA, Jossey-Bass).

EGAN, G. \& COWAN, M.A. (1979) People in Systems: a Model for Development in the HumanService Professions and Education (Monterey, CA, Brooks/Cole). 